\title{
Optimization of a Gating System by Means of Simulation Software to Eliminate Cold Shut Defects in Casting
}

\author{
Vladimír Šabík $k^{a^{*}}$, Peter Futáša ${ }^{a}$, Alena Pribulováa ${ }_{(\mathbb{C})}$, Petra Delimanováa $^{(1)}$ \\ ${ }^{a}$ Technical University of Kosice, Faculty of Materials, Metallurgy and Recycling, Letná 9 Košice, Slovakia
}

*e-mail: vladimir.sabik@tuke.sk

(C) 2021 Authors. This is an open access publication, which can be used, distributed and reproduced in any medium according to the Creative Commons CC-BY 4.0 License requiring that the original work has been properly cited.

Received: 5 February 2021/Accepted: 17 March 2021/ Published online: 30 March 2021

This article is published with open access at AGH University of Science and Technology Press

\begin{abstract}
The current trend in foundries is to achieve the production of high quality and competitive cast components. The innovation and optimization of current processes is a necessary element to achieve this goal. With the help of numerical simulations, it is possible to replace financially demanding and time-consuming experiments in real conditions with simulations that can reliably represent foundry process using computer technology. By a detailed analysis of the simulation results, we can predict various risks that could negatively affect the production process. This article monitors the influence of changes in the design of the gating system on the surface quality of a clutch wheel casting made of ductile iron, in the production of which two models of the gating system for casting were constructed in CAD software. Verification of gating systems was performed using the simulation software NovaFlow \& Solid. The aim of the design change of the gating system is to reduce the amount of liquid metal used per casting, which can have a significant economic impact on industrial production. For this purpose, several simulations of the gating system of the casting were performed, while 2 which are the most representative for the mentioned problem were selected for the needs of the article. The main task of the simulation was to set the cellular network and conditions as close as possible to the reality of casting and the subsequent design and modification of the gating system.
\end{abstract}

\section{Keywords:}

numerical simulations, gating system, clutch wheel, cold shut

\section{INTRODUCTION}

In the production of each casting component, an effort is made to achieve the required quality at the lowest possible cost. Through simulation software it is possible to simulate processes with a relatively high degree of accuracy during the casting of liquid metal and the solidification of the casting. In the production of quality castings, the simulation of filling and solidification of castings is an integral part of production quality. Computer simulation of casting processes is a highly effective tool for optimizing processes and events that take place during the filling of the mould cavity and casting cooling. In the pre-production stage, flaws in castings such as shrinkages and micro porosity can be prevented by the simulation of filling and solidification. Adjustments to the gating and feeder systems, along with technological adjustment of casting and casting parameters by means of a computer simulation, can help to prevent such flaws [1-4].

Numerical simulations are a tool that can be used to evaluate foundry processes by means of computer technology and to analyze various risks that might adversely affect the production process. By using software and setting the input data correctly, it is possible to favorably influence and even eliminate the trial and error method which has long been used in some foundries. By direct optimization, it is possible to not only reduce the input costs to produce a given series of castings but also the costs associated with determining the cause of the defect. The digitizing of the production process in the foundry should consist of two main steps [5]:

- execution of a 3D model in CAD system (Catia, SolidWorks, Autodesk 360),

- implementation of foundry process simulations in a simulation software (Magmasoft, Novaflow, ProCast).

Numerical modeling in the foundry industry is based on the use of empirical and semi-empirical physical and numerical models [6]. By using simulation software, which already includes a numerical model describing the processes taking place in the foundry process, we obtain sophisticated solutions of complex processes, which can be subsequently analyzed. Commercially available software packages that are currently available for foundry needs are affordable and can replace demanding operational experiments [7]. 
The casting simulation software consists of three modules:

- solidification simulations,

- flow simulations,

- combined simulation.

The solidification simulation can be used to detect the location of hot spots, to design and modify gating system. The flow simulation can help us to visualize melt velocity during mold filling, filling time and solidification time, which helps to locate melt flow disturbances such as imperfect melt flow, gating system malfunction, etc. $[8,9]$.

\section{EXPERIMENTAL PART}

The 3D model of the casting (Fig. 1) with many rib parts was created in CAD software SolidWorks. The computer simulations were realized by the software NovaFlow \& Solid.

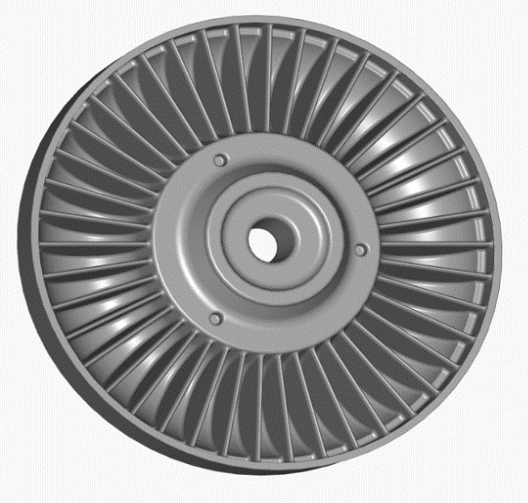

Fig. 1. 3D model of casting

The EN-GJS-500 alloy was the model material. The melt flow was $11 \mathrm{~kg} \cdot \mathrm{s}^{-1}$, the casting type was gravity casting. The melt was poured into the mold made of uniform bentonite mixture. After creating individual variants of the gating system in the CAD software SolidWorks, it is necessary to import the 3D model into the simulation program NovaFlow \& Solid, and configure the input parameters of the simulations so that they correspond as much as possible to real conditions.

Table 1 shows the summary of simulation inputs.

Table 1

Summary of simulation inputs

\begin{tabular}{cc}
\hline Casting type & Gravity casting \\
\hline Alloy & EN-GJS-500 \\
\hline Flow & $11 \mathrm{~kg} \cdot \mathrm{s}^{-1}$ \\
\hline Casting temperature & $1410^{\circ} \mathrm{C}$ \\
\hline
\end{tabular}

In Figure 2, the entire system is imported into a simulation program. A cell in a model is an element in which a program can evaluate individual processes (the more cells, more accurate the results). As the number of cells increases, the computation time of the simulation increases, too.

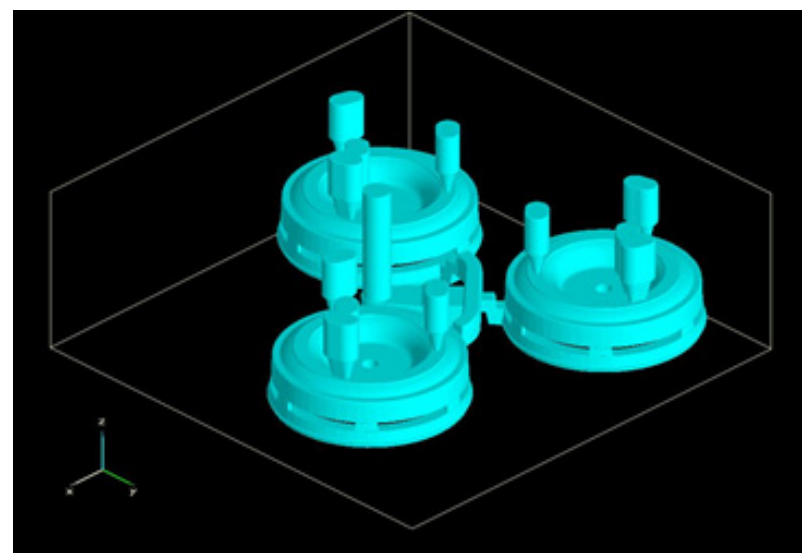

Fig. 2. The cellular network of the model imported in the simulation software NovaFlow \& Solid

\section{SIMULATIONS}

During the casting production, there was insufficient flow of molten metal into the ribbed parts. Figure 3 shows a 3D model of the original implemented design of the gating system with 3 castings.

a)

b)
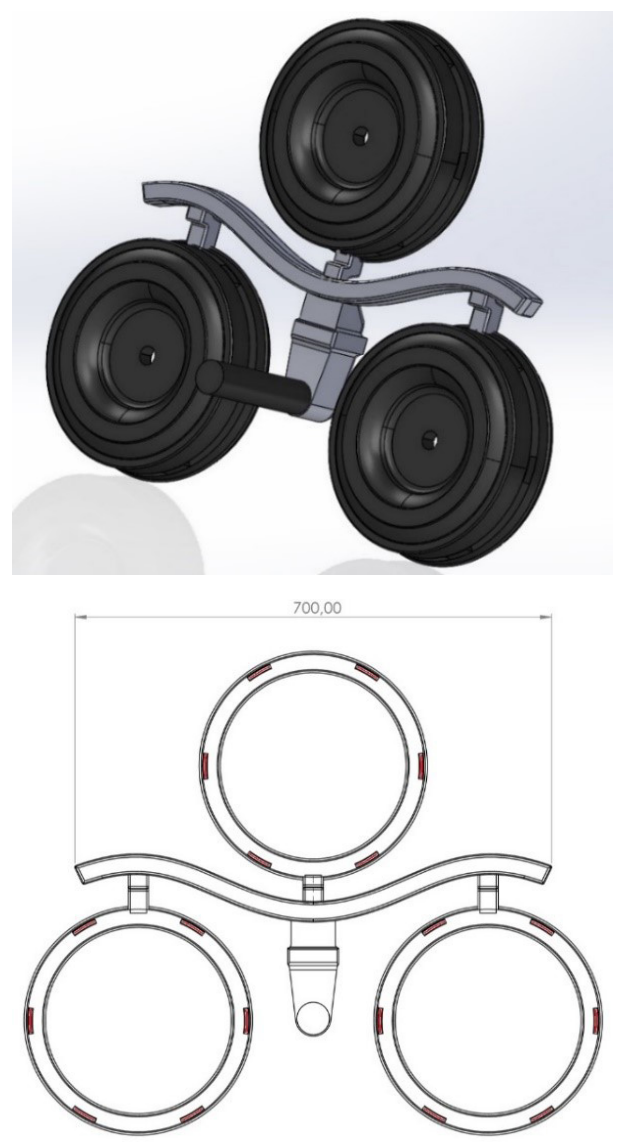

Fig. 3. Gating system with 3 castings: a) 3D model; b) original design

After the observed simulation of the original design (Fig. 4), it was found that at the value of $49 \%$ of the mold filling, the melt was flowing from outside of the ribs of the casting towards central part, which comes into contact with the melt, which was flowing in the opposite direction. The contact area in these places is too large due to the flowing melt volume through this cross section. 

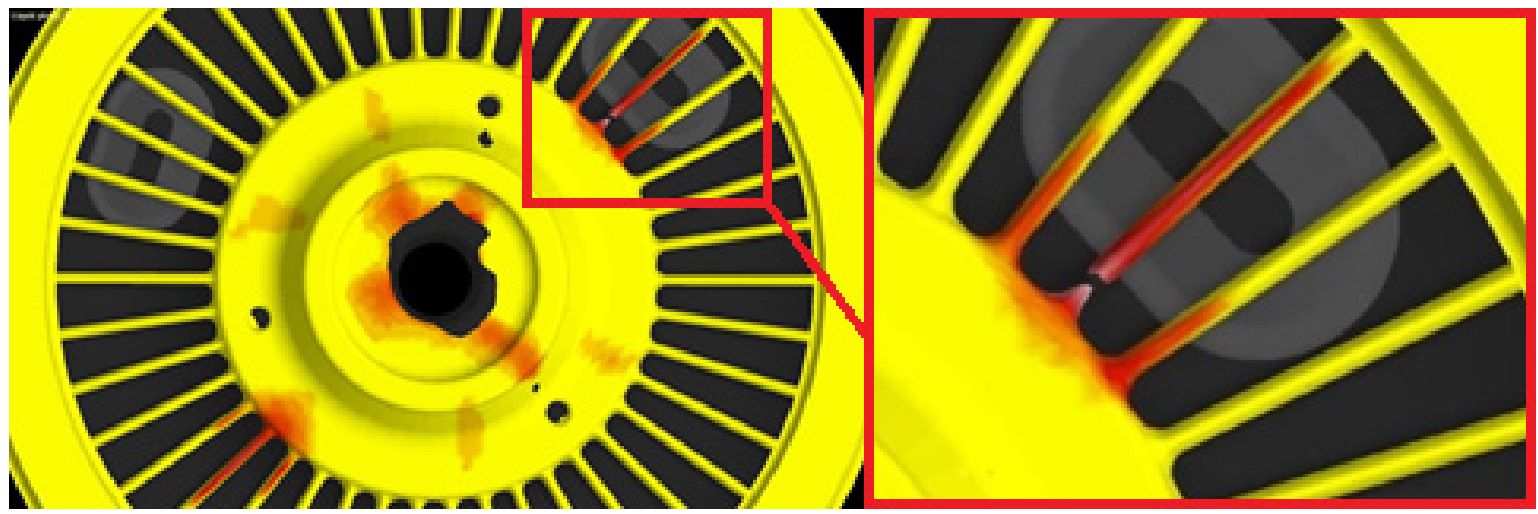

Fig. 4. The original design of the $49 \%$ filled form - detail of risk areas

In Figure 4, we can see red (high proportion of liquid phase) and in some places gray color (solidified metal), which corresponds to the real occurrence of defects in the casting. Therefore, this point was chosen for investigation. The form reaches $49 \%$ filling in the time of $3.460 \mathrm{~s}$. These factors can cause the defect known as cold-shut. Cold-shuts are visible on the casting as missing part of the casting without fracture.

Figure 5 shows the improved gating system of the casting.

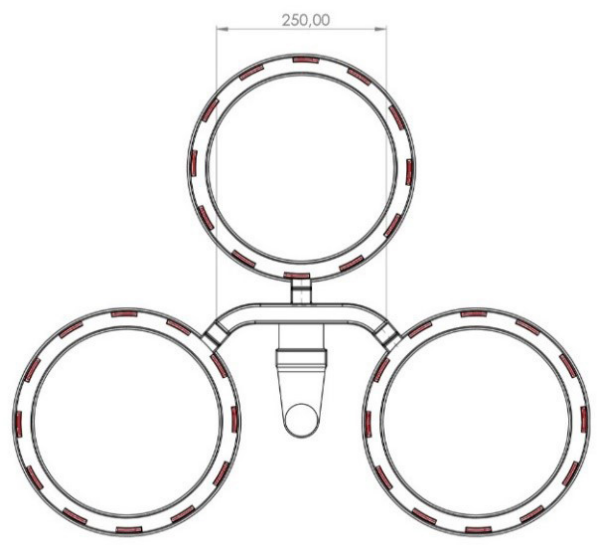

Fig. 5. Improved gating system

Figure 6 shows the proportion of liquid phase only. This indicates directional solidification and the casting should solidify without defects. At the same time, the form reaches the 49 filling in the time $3.168 \mathrm{~s}$ after changing the gating system design.

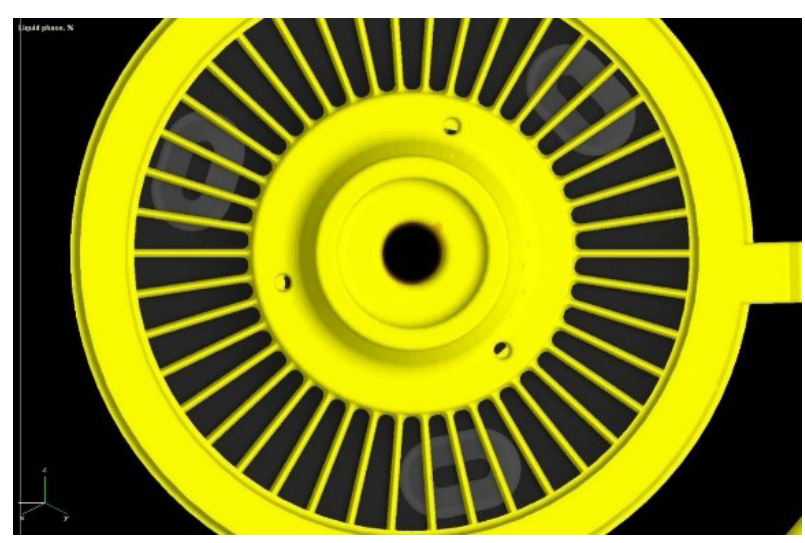

Fig. 6. The improved gating system of the $49 \%$ filled mold - the detail of risk areas

\section{CONCLUSION}

Results are based on mold filling simulation as well as solidification simulation. Those methods were used to reveal the possible cause of the casting defect. The construction modification of the gating system eliminated the cause of the casting defect by means of the faster distribution of molten metal into risk areas. The filling time of the mold in the case of the original design of the gating system was $3.460 \mathrm{~s}$. In the case of the improved gating system, the filling time was $3.168 \mathrm{~s}$, and this difference in times led to the elimination of the occurrence of the defect. Improvement of the gating system design would significantly suppress the occurrence of the defect and represent economic savings in terms of cast iron consumption.

We can see the important difference between the weight of the original design of the gating system and the variant with the improved gating system of up to $4 \mathrm{~kg}$. This weight difference represents 4 of cast iron per year for mass production. The costs associated with the casting of test specimens would help to achieve the elimination of defects and would significantly reduce failures in casting.

\section{Acknowledgements}

This work was supported by the Scientific Grant Agency of The Ministry of Education of the Slovak republic No. KEGA 003TUKE-4/2021 and APVV-19-0559.

\section{REFERENCES}

[1] Olofsson J., Salomonsson K. \& Svensson I.L. (2015). Modelling and simulations of ductile iron solidification-induced variations in mechanical behaviour on component and microstructural level. IOP Conference Series: Materials Science and Engineering, 84, 12026. Doi: https://doi.org/10.1088/1757-899X/84/1/012026.

[2] Sulamet-Ariobimo R.D., Soedarsono J.W. \& Suharno B. (2015). Cooling Rate Analysis of Thin Wall Ductile Iron Using Microstructure Examination and Computer Simulation. Applied Mechanical and Materials, 752-753, 845-850. Doi: https:// doi.org/10.4028/www.scientific.net/AMM.752-753.845.

[3] Bhatt H., Barot R., Bhatt K., Beravala H. \& Shah J. (2014). Design Optimization of Feeding System and Solidification Simulation for Cast Iron. In: Procedia Technology. $2^{\text {nd }}$ International Conference on Innovations in Automation and Mechatronics Engineering, ICIAME 2014, Gujarat, India, 7-8 March, 14, 357-364. Retrieved from https://www.sciencedirect.com/science/article/pii/S221$-2017314000826$. 
[4] Futáš P., Pribulová A., Fedorko G., Molnár V., Junáková A. \& Laskovský V. (2019). Failure analysis of railway brake disc with the use of casting process simulation. Engineerign Failure Analysis, 95, 226-238. Doi: https://doi.org/10.1016/j.engfailanal.2018.09.005

[5] Jolly M. (2002). Casting simulation - How well do reality and virtual casting match? State of the art review. International Journal of Cast Metals Research, 14(5), 303-313. Doi: https:// doi.org/10.1080/13640461.2002.11819448.

[6] Novacast (2018). Release of NovaFlow\&Solid 6.4. Retrieved from https://www.novacast.se/news/release-of-novaflowsolid-6-4/ (accessed 1.02.2021).

[7] MAGMASOFT囚 5.4 - Autonomous Engineering. Retrieved from https://www.magmasoft.co.in/export/shared/.galleries/pdfs_publications/2018_pm_en_magmasoft_rel_5_4.pdf (accessed 5.02.2021).
[8] Zexuan W., Tao H., Yong Y. \& Yan L. (2015). Application and development of numerical simulation technology in Casting. International Journal of Research in Engineering and Science (IJRES), 3(2), 23-28. Retrieved from https://www.academia.edu/12390402/ Application_and_development_of_numerical_simulation_technology_in_Casting?sm=b (accessed 26.02.2021).

[9] Ha J., Cleary P., Alguine V. \& Nguyen T. (1999). Simulation of die filling in gravity die casting using SPH and MAGMAsoft. In: Second International Conference on CFD in the Minerals and Process Industries, CSIRO, Melbourne, Australia, 6-8 December, 423-428. Retrieved from http://www.cfd.com.au/cfd_conf99/ papers/045HA.PDF (accessed 5.02.2021). 